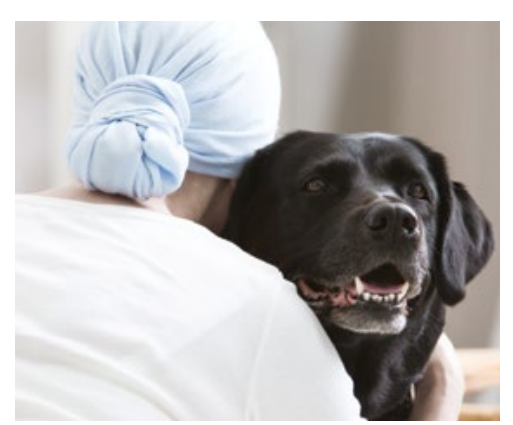

CPD

Jaclyn Yoong, Peter Poon

\section{Background}

Pain remains one of the most significant symptoms of cancer. Impeccable assessment and understanding of the cause and mechanism of pain, pragmatic prescribing (including avoiding dogmatic opioid dose increments) and consideration of all modalities of interventions are central to optimal treatment.

\section{Objectives}

This paper outlines aspects of cancer pain assessment, provides a mechanistic framework to facilitate analysis and guide treatment, and emphasises the need for ongoing assessment of treatment efficacy and toxicities. We discuss pharmacological and interventional treatment options and some cancer pain syndromes.

\section{Discussion}

Management of cancer pain should be proactive and driven by an understanding of pain mechanisms, cancer behaviour and trajectories. It should include optimal use of multimodality interventions alongside directed anti-cancer therapies as appropriate, in consultation with pain or palliative medicine physicians.

\title{
Principles of cancer pain management
}

\author{
An overview and focus on pharmacological \\ and interventional strategies
}

CANCER PAIN is one of the most common and problematic symptoms faced in palliative care. Despite advances in cancer treatment and palliative care, pain has been reported to be moderate to severe in as many as $51.9 \%$ of patients with advanced disease and $38 \%$ of all patients. ${ }^{1}$ Uncontrolled pain often results in unnecessary suffering; it can have an impact on quality of life and interfere with activities of daily living, even affecting basic functions such as mobility and sleep. Uncontrolled pain also decreases patients' ability to cope with illness and can disrupt ongoing anti-cancer treatment. ${ }^{2}$ Barriers to appropriate management of cancer pain include fear and apprehension by clinicians and patients. Clinicians may hesitate to increase opioid dosages when appropriate because of misconceptions about opioids causing respiratory depression, addiction, or decreased life expectancy. Similarly, patients can be 'opiophobic', which, in turn, can result in under-reporting of pain. ${ }^{3}$

A comprehensive assessment and understanding of the pain are essential. One should consider if the pain is related to the underlying cancer, intervention or treatment complications or if there is a separate cause of the pain, and whether it is consistent with known cancer pain syndromes.

In regard to interventions, broadly speaking, there are pharmacological and non-pharmacological methods. In 1986, the original World Health Organization (WHO) three-step pain ladder was published; it recommended a gradual increase in analgesic potency, starting with non-opioids and stepping up to weak and then strong opioids (dosing according to pain severity), and adding adjuvant analgesics as required at any step. Importantly, the WHO recommendation also focused on a 'total' or holistic approach to pain assessment that includes physical, psychological, spiritual and social factors. It also suggested the use of anaesthetic blocks, neurosurgical procedures and anti-cancer treatments. ${ }^{4}$ Some proposed modifications to the original three-step ladder have included elimination of the second step (weak opioids) as well as addition of another step for interventional techniques. ${ }^{5}$

Relief from cancer pain is entrenched within the purview of palliative care. According to the WHO definition of palliative care, pain management can be provided 'in conjunction with other therapies that are intended to prolong life, such as chemotherapy or radiation therapy, and includes those investigations needed to better understand and manage distressing clinical complications', together with management of other symptoms, care coordination and advanced care planning, and care of family members. ${ }^{6}$ Management of cancer pain in palliative care needs to be within the context of the patient's goals of care and limitations of interventions that may be futile, burdensome and against the patient's or family's wishes.

The aim of this paper is to provide an overview of conventional pharmacological interventions and 
interventional techniques in cancer pain management. When considering treatment choices, clinicians must always consider the role of disease-modifying anti-cancer therapies (eg surgery, radiation or systemic anti-cancer drugs) to treat the cause of pain.

\section{Pain assessment}

Characteristics of the pain should be sought when taking a clinical history: quality, site, severity, radiation, temporal features, and factors that precipitate, exacerbate or relieve the pain. Severity may be rated verbally, on a numerical scale or with validated scales such as a visual analogue scale. Temporal features include acute versus chronic pain - acute onset may indicate sudden complications, such as haemorrhage, fracture or bowel obstruction, while chronic pain may suggest ongoing tumour-related effects. Pain may also be background versus incident in nature; the latter is often seen in bone pain, where pain occurs acutely with movement and is short-lived. ${ }^{7}$

Where possible, pain assessment should rely on the patient's description. The history should be evaluated in conjunction with physical examination and information from relevant investigations about the extent of disease, treatments and other comorbidities. Psychological and cultural factors should always be considered. The practitioner should determine the meaning of the pain to the patient and the level of pain control that the patient considers desirable and achievable.

\section{Mechanisms of cancer pain}

Consideration of the mechanism underlying the pain can assist in determining the analgesic treatment that should be used as first-line. ${ }^{8}$ Although clinical research on the effectiveness of a mechanistic approach is limited, using this framework ensures consideration of underlying pathology and aetiology of pain. Two main mechanistic categories are nociceptive and neuropathic pain. Nociceptive pain can be divided into somatic or visceral types: somatic pain can be superficial (eg involving skin or mucosa) or deep (eg involving bone, muscle and tendons), and visceral pain involves internal organs, such as the lungs, liver, bowel and heart. Neuropathic pain is due to nerve compression or injury. Cancer

Table 1. Mechanistic classification of cancer pain ${ }^{9}$

\begin{tabular}{|c|c|c|c|c|}
\hline \multicolumn{3}{|l|}{ Nociceptive pain } & \multicolumn{2}{|l|}{ Neuropathic pain } \\
\hline Superficial somatic & Deep somatic & Visceral & Pure & Mixed \\
\hline $\begin{array}{l}\text { Originates in: } \\
\text { - Skin } \\
\text { - Subcutaneous tissue } \\
\text { - Mucosa of mouth, nose, } \\
\text { sinuses, urethra, anus }\end{array}$ & $\begin{array}{l}\text { Originates in: } \\
\text { - Bone, joints, muscles, } \\
\text { tendons, ligaments } \\
\text { - Superficial lymph nodes } \\
\text { - Organ capsules and } \\
\text { mesothelial membranes } \\
\text { (pleura and peritoneum) }\end{array}$ & $\begin{array}{l}\text { Originates in: } \\
\text { - Solid or hollow organs } \\
\text { - Deep tumour masses } \\
\text { - Deep lymph nodes } \\
\text { - Large muscle groups }\end{array}$ & $\begin{array}{l}\text { De-afferentation, no } \\
\text { nociceptive element }\end{array}$ & $\begin{array}{l}\text { Nociceptive element } \\
\text { due to tumour invasion } \\
\text { or compression of } \\
\text { nerve pathway }\end{array}$ \\
\hline Burning or stinging pain & $\begin{array}{l}\text { Dull, aching pain, } \\
\text { aggravated by movement }\end{array}$ & Dull, deep pain & \multicolumn{2}{|c|}{$\begin{array}{l}\text { Dysaesthesia (abnormal sensation of pins and } \\
\text { needles, tingling, burning pain in a numb area) } \\
\text { Allodynia (due to a stimulus that does not } \\
\text { normally cause pain) } \\
\text { Lancinating or shooting pain } \\
\text { Phantom pain }\end{array}$} \\
\hline $\begin{array}{l}\text { Well defined and localised } \\
\text { to site of pain stimulus, } \\
\text { local tenderness }\end{array}$ & $\begin{array}{l}\text { Well defined and localised } \\
\text { to site of pain stimulus, } \\
\text { local tenderness }\end{array}$ & $\begin{array}{l}\text { Poorly localised, may } \\
\text { be tender }\end{array}$ & \multicolumn{2}{|c|}{ Nerve or dermatome distribution } \\
\hline $\begin{array}{l}\text { No referral or autonomic } \\
\text { effects }\end{array}$ & $\begin{array}{l}\text { May be referred, but no } \\
\text { autonomic effects }\end{array}$ & $\begin{array}{l}\text { May be referred and } \\
\text { have autonomic effects } \\
\text { including nausea, } \\
\text { vomiting, sweating, blood } \\
\text { pressure and heart rate } \\
\text { changes }\end{array}$ & \multicolumn{2}{|c|}{$\begin{array}{l}\text { Referred, no local tenderness } \\
\text { Autonomic instability resulting in warmth, } \\
\text { sweating, pallor, cold, cyanosis (localised to } \\
\text { nerve pathway) }\end{array}$} \\
\hline $\begin{array}{l}\text { Examples: } \\
\text { - Malignant ulcers } \\
\text { - Stomatitis }\end{array}$ & $\begin{array}{l}\text { Examples: } \\
\text { - Bone metastases } \\
\text { - Liver capsule distension } \\
\text { or inflammation }\end{array}$ & $\begin{array}{l}\text { Examples: } \\
\text { - Intestinal, biliary, } \\
\text { ureteric colic }\end{array}$ & $\begin{array}{l}\text { Examples: } \\
\text { - Post-herpetic } \\
\text { neuralgia } \\
\text { - Post-thoractomy } \\
\text { syndrome } \\
\text { - Phantom pain }\end{array}$ & $\begin{array}{l}\text { Examples: } \\
\text { - Brachial, } \\
\text { lumbosacral plexus } \\
\text { - Chest wall invasion } \\
\text { - Spinal cord } \\
\text { compression }\end{array}$ \\
\hline
\end{tabular}


pain is often a combination of nociceptive and neuropathic pain..$^{9,10}$ Table 1 illustrates an example of a mechanistic framework for assessing pain.

\section{Pharmacological interventions}

A helicopter view of pharmacological interventions is discussed in the introduction. In cancer pain, which is often moderate or severe, opioid therapy is generally the first-line approach. The majority of people with cancer pain will need opioid analgesics at some point. ${ }^{11}$ When opioids alone do not adequately treat the pain, one may consider the addition of other analgesics: either non-opioid or adjuvant analgesics. In mechanistic terms, most categories of cancer pain will respond to opioid medication; however, other analgesics are useful for management of neuropathic and refractory pain. ${ }^{12}$ Targeted use of several analgesics together, each with a different site of action, can be effective, especially in the setting of refractory pain.

\section{Opioids}

Opioids bind to mu, kappa, and delta receptors present in the peripheral and central nervous system. Morphine is the prototype opioid drug and is a pure mu-agonist that is primarily metabolised in the liver. Its metabolites are renally excreted; therefore, morphine use in patients with renal insufficiency is generally not recommended because of accumulation of metabolites and potential toxicities. Oxycodone binds to mu and kappa receptors, and is available in a combination preparation with naloxone, to minimise the side effects of constipation. Naloxone, an opioid antagonist, is poorly absorbed when taken orally and thus remains in the gastrointestinal tract, where it reduces local side effects. However, the oxycodone/naloxone combination should be avoided when there is moderate or severe hepatic dysfunction, as this may lead to increased serum levels of naloxone. ${ }^{13}$

Hydromorphone is a potent, hydrophilic opioid. Its metabolites are renally cleared, but the concentration appears to be low and relatively safe. Morphine, oxycodone and hydromorphone are available in oral and parenteral forms; in oral forms there are slow-release, long-acting forms as well as rapid-onset, short-acting forms. Fentanyl is highly lipophilic and is available in transdermal, parenteral and, more recently, transmucosal form. While fentanyl patches can be useful for chronic, stable pain (and require changing every two to three days), transmucosal fentanyl is very fast-acting. Methadone is a mu-receptor agonist opioid with N-methyl-D-aspartate (NMDA) inhibitor properties. Fentanyl is metabolised by the cytochrome P450 system. It has a highly variable and prolonged half-life, with the potential for many drug interactions that can affect its serum levels. Therefore, while methadone can be very effective for refractory and complex cancer pain, the risk of accumulation and potential overdose means that it is best prescribed by a pain or palliative medicine specialist. Finally, the partial agonist buprenorphine is available in transdermal form for chronic pain. ${ }^{14}$

\section{Opioid rotation}

Switching from one opioid to another is recommended if a particular opioid fails to provide adequate analgesia, or rapid tolerance is seen, or if toxicity or adverse effects develop. Opioid rotation can improve response and/or reduce intensity of side effects; however, changing opioids can be challenging as there is limited evidence supporting dose conversions used in clinical practice. Recommended conversions are often approximations, and there is individual variation in opioid response. Furthermore, switching opioids often occurs in situations of complex, refractory pain where high doses of drug are often involved, rather than in stable situations, and the balance between adequate analgesia and side effects can be difficult to achieve. The conversion should not be purely mathematical but should also consider previous opioid therapy, concurrent medications, adverse effects, and the underlying clinical situation including organ function and comorbidities. Thus, opioid rotation, while potentially beneficial, needs to be done with caution; consultation with and supervision by an experienced pain or palliative care specialist is recommended. ${ }^{15,16}$

\section{Non-opioid analgesics}

Non-opioid medications include paracetamol, non-steroidal antiinflammatory drugs (NSAIDs) and steroids. Paracetamol (or acetaminophen) inhibits prostaglandin formation and can be useful for mild pain. NSAIDs and steroids also inhibit prostaglandin formation: NSAIDs by inhibiting the enzyme cyclooxygenase, and steroids by inhibiting phospholipase A2. NSAIDs and steroids should be considered when treating somatic pain. Steroids reduce pain intensity through their antiinflammatory effect and by reducing vascular permeability (ie by reducing oedema, which can be effective in the setting of a tumour causing mass effect). Dexamethasone is the steroid commonly used for cancer pain. Long-term side effects of steroids are well documented and include immunosuppression, hyperglycaemia, myopathy, osteoporosis and Cushing's syndrome. ${ }^{17}$

\section{Adjuvant analgesics}

Adjuvant analgesics are drugs primarily marketed for other indications, such as depression, but also have an important role in cancer pain management. Antidepressants, such as serotoninnorepinephrine reuptake inhibitors (eg duloxetine, venlafaxine) or tricyclics (eg nortriptyline, amitriptyline) and anticonvulsants (eg pregabalin, gabapentin, carbamazepine) have welldocumented efficacy in the treatment of pain, particularly neuropathic pain. ${ }^{12,18,19}$ Ketamine is a controversial NMDA antagonist with analgesic effects in refractory cancer pain; its use is potentially limited by lack of evidence and neurocognitive side effects. ${ }^{20}$

Tramadol and tapentadol are analgesics that combine mu receptor activity and monoamine reuptake blockade; however, at this stage their role in cancer pain remains unclear. 


\section{Interventional techniques}

Interventional techniques may be appropriate adjuvants or alternatives to ongoing systemic pharmacological treatment. They may reduce the required opioid dosage and therefore be beneficial for patients with medication side effects. Commonly used interventional therapies include neural blockade, neuraxial infusion and vertebral augmentation procedures. $^{21}$

\section{Neural blockade}

Non-neurolytic blocks involve injection of a steroid, sometimes with local anaesthetic, into the region of the affected peripheral nerve(s) to provide analgesia. These can be performed using bolus injection (single or repeated for sustained effect) or continuous infusion of a local anaesthetic.

Neurolytic blocks produce analgesia by destroying afferent neural pathways or sympathetic structures involved in pain transmission, and are therefore useful in neuropathic or visceral pain in the distribution of specific peripheral or autonomic nerves. Chemical neurolysis (eg with ethyl alcohol or phenol) is more commonly used. Other techniques of neural destruction include neurosurgical procedures (ie rhizotomy, cordotomy and myelotomy), radiofrequency ablation and cryotherapy. ${ }^{22}$ Common examples of neurolytic blocks are coeliac plexus block for epigastric or intra-abdominal visceral pain and ganglion impar block for visceral pain of the perineum.

\section{Neuraxial infusion}

Neuraxial infusion involves continuous infusion of medication into either the epidural or intrathecal space by means of temporary or permanent catheters and implanted pumps. These methods are effective for intractable pain and provide highly selective pain relief while minimising toxicity because of the significantly reduced concentration and dosage of drugs (opioid and local anaesthetic) needed. However, use of these techniques is limited in palliative care settings, often because of limited resources, familiarity and skill, as well as patients' limited life expectancies. ${ }^{21}$

\section{Vertebral augmentation procedures}

Vertebral augmentation procedures involve injection of bone cement under imaging guidance into the affected vertebral body to relieve pain and stabilise the fractured vertebrae. There is evidence to support improved pain and function and reduced medication use in patients with painful spinal metastases or myeloma. Complication rates are low; specific complications include cement leakage and neural damage. ${ }^{23}$

\section{Cancer pain syndromes}

Cancer pain syndromes are typified by a constellation of pain characteristics, physical signs and investigative findings. The specific management of three common syndromes encountered in practice is discussed.

\section{Bone metastases}

Pain may be due to direct invasion, secondary pathological fracture or damage to adjacent structures. Vertebral pain syndromes may result in local or radicular pain, with accompanying neurological features. Incident pain is common, especially when weightbearing is affected; use of breakthrough analgesia with fast-acting opioids such as transmucosal fentanyl is key. Specific therapeutic considerations include radiotherapy and bisphosphonates and, from an interventional perspective, vertebral augmentation procedures or orthopaedic surgery for fracture stabilisation. $^{24}$

\section{Locally advanced pancreatic cancer}

As a result of visceral invasion, the pain experienced in locally advanced pancreatic cancer is commonly described as gnawing epigastric pain. It often has a significant neuropathic component due to infiltration of the coeliac plexus, described as pain radiating bilaterally and into the back. In conjunction with opioids, NSAIDS or steroids, and/or an adjuvant analgesics, imaging-guided or endoscopic ultrasoundguided chemical neurolysis of the coeliac plexus can be used, with reported improvements in pain and quality of life for approximately $8-12$ weeks. ${ }^{25}$

\section{Head and neck cancer}

Pain can be tumour-related and/or treatment-related following radiotherapy or previous surgery. Tumour-related and post-surgical pain is classically neuropathic in nature. The most common acute oral side effect of radiotherapy is oral mucositis. Topical local anaesthetic mouthwashes or opioid-based ones can be effective, albeit for a short duration. If needed, administering analgesics via alternative routes (ie via feeding tube, transdermal or parenteral routes) should be considered, with an emphasis on using neuropathic agents such as gabapentin, pregabalin or amitriptyline. ${ }^{26}$ Although evidence is lacking, ketamine is reportedly effective in the treatment of neuropathic and mucositis-related pain, and some clinicians use this in a 'burst' protocol via subcutaneous infusion. ${ }^{20,27}$

\section{Conclusion}

General practitioners have an integral role in cancer pain management. With in-depth longitudinal knowledge and care of the patient, they are well placed to provide best holistic pain management. Promotion of opioid use through the WHO pain ladder has been well embraced by general practice; however, dogmatically following guidelines and rapidly increasing opioid dosage can hinder best treatment and promote adverse effects. Instead, understanding analgesic pharmacology and the underlying mechanisms of pain will assist in determining drug selection. Knowledge of the underlying cancer, its disease trajectory and common pain syndromes also fosters a more proactive rather than reactive approach to pain management, including use of concurrent analgesics, opioid rotation and timely consideration of appropriate interventional techniques. Regular pain assessment, monitoring and evaluation of interventions for efficacy and potential side effects are essential. Furthermore, there are many useful resources that are available to provide information and guidance, in print and online. Some examples are provided below. Finally, in cases of complex and/or refractory pain, 
referral to a pain or palliative medicine specialist is recommended.

\section{Resources for general practitioners}

- Expert Group for Palliative Care. Palliative care. In: eTG complete [internet]. Melbourne: Therapeutic Guidelines Limited, 2018.

- CareSearch, www.caresearch.com.au

- PalliativeDrugs.com, www.palliativedrugs.com

\section{Authors}

Jaclyn Yoong MBBS (Hons), FRACP, FAChPM, MPH Palliative Care Physician and Medical Oncolgoist, Supportive and Palliative Care Unit, Monash Health; Adjunct Lecturer, Monash University, Vic

Peter Poon MBBS, PGDipPM, FRACGP, FAChPM, Palliative Care Physician, Supportive and Palliative Care Unit, Monash Health; Adjunct Associate Professor, Monash University, Vic. peter.poon@ monashhealth.org

Competing interests: None.

Funding: None.

Provenance and peer review: Commissioned, externally peer reviewed.

\section{References}

1. van den Beuken-van Everdingen $\mathrm{MH}$, Hochstenbach LM, Joosten EA, Tjan-Heijnen VC, Janssen DJ. Update on prevalence of pain in patients with cancer: Systematic review and meta-analysis. J Pain Symptom Manage 2016;51(6):1070-90.e9. doi: 10.1016/j. jpainsymman.2015.12.340.

2. Greco MT, Roberto A, Corli O, et al. Quality of cancer pain management: An update of a systematic review of undertreatment of patients with cancer. J Clin Oncol 2014;32(36):4149-54. doi: 10.1200/JCO.2014.56.0383.

3. Scarborough BM, Smith CB. Optimal pain management for patients with cancer in the modern era. CA Cancer J Clin 2018;68(3):182-96. doi: 10.3322/caac.21453.

4. World Health Organization. Cancer: WHO's cancer pain ladder for adults. Geneva: WHO, 2018. Available at www.who.int/cancer/palliative/ painladder/en [Accessed 1 July 2018].

5. Vargas-Schaffer G. Is the WHO analgesic ladder still valid? Twenty-four years of experience. Can Fam Physician 2010;56(6):514-17, e202-5.

6. World Health Organization. Cancer: WHO definition of palliative care. Geneva: WHO, 2018. Available at www.who.int/cancer/palliative/ definition/en [Accessed 1 July 2018].

7. Ripamonti Cl, Santini D, Maranzano E, Berti M, Roila F; ESMO Guidelines Working Group. Management of cancer pain: ESMO clinical practice guidelines. Ann Oncol 2012;23 Suppl 7:vii139-54. doi: 10.1093/annonc/mds233

8. Caraceni A, Portenoy RK. An international survey of cancer pain characteristics and syndromes. IASP Task Force on Cancer Pain. International Association for the Study of Pain. Pain 1999;82(3):263-74.
9. Ashby MA, Fleming BG, Brooksbank M, et al. Description of a mechanistic approach to pain management in advanced cancer. Preliminary report. Pain 1992;51(2):153-61.

10. Knudsen AK, Aass N, Fainsinger R, et al. Classification of pain in cancer patients - A systematic literature review. Palliat Med 2009;23(4):295-308. doi: 10.1177/0269216309103125.

11. Quigley C. Opioids in people with cancer-related pain. BMJ Clin Evid 2008;2008:2408.

12. McMenamin E. Pain management principles. Curr Probl Cancer 2011;35(6):317-24. doi: 10.1016/j. currproblcancer.2011.10.006.

13. DePriest AZ, Miller K. Oxycodone/naloxone: Role in chronic pain management, opioid-induced constipation, and abuse deterrence. Pain Ther 2014;3(1):1-15. doi: 10.1007/s40122-014-0026-2.

14. Expert Group for Palliative Care. Palliative care. In: eTG complete [internet]. Melbourne: Therapeutic Guidelines Limited, 2018.

15. Mercadante S, Bruera E. Opioid switching in cancer pain: From the beginning to nowadays. Crit Rev Oncol Hematol 2016;99:241-48. doi: 10.1016/j. critrevonc.2015.12.011.

16. Mercadante S. Opioid rotation for cancer pain: Rationale and clinical aspects. Cancer 1999;86(9):1856-66.

17. Leppert W, Buss T. The role of corticosteroids in the treatment of pain in cancer patients. Curr Pain Headache Rep 2012;16(4):307-13. doi: 10.1007/ s11916-012-0273-z.

18. Verdu B, Decosterd I, Buclin T, Stiefel F Berney A. Antidepressants for the treatment of chronic pain. Drugs 2008;68(18):2611-32. doi: 10.2165/0003495-200868180-00007.

19. Dworkin RH, O'Connor AB, Backonja M, et al. Pharmacologic management of neuropathic pain: Evidence-based recommendations. Pain 2007;132(3):237-51. doi: 10.1016/j. pain.2007.08.033.

20. Jackson K, Ashby M, Howell D, et al. The effectiveness and adverse effects profile of 'burst' ketamine in refractory cancer pain: The VCOG PM 1-00 study. J Palliat Care 2010;26(3):176-83.

21. International Association for the Study of Pain. Interventional techniques for cancer pain. Washington DC: IASP, 2009. Available at https://s3.amazonaws.com/rdcms-iasp/files/ production/public/Content/ContentFolders/ GlobalYearAgainstPain2/CancerPainFactSheets/ InterventionalTechniques_Final.pdf [Accessed 1 July 2018].

22. Teddy PJ. The role of neurosurgery in the treatment of chronic pain. Med J Aust 2016;204(8):287-88.

23. Chandra RV, Meyers PM, Hirsch JA, et al. Vertebral augmentation: Report of the Standards and Guidelines Committee of the Society of Neurolnterventional Surgery. J Neurointerv Surg 2014;6(1):7-15. doi: 10.1136/ neurintsurg-2013-011012.

24. Smith HS. Painful osseous metastases. Pain Physician 2011;14(4):E373-403.

25. Drewes AM, Campbell CM, Ceyhan GO, et al. Pain in pancreatic ductal adenocarcinoma: A multidisciplinary, International guideline for optimized management. Pancreatology 2018;18(4):446-57. doi: 10.1016/j.pan.2018.04.008.

26. Mirabile A, Airoldi M, Ripamonti $C$, et al. Pain management in head and neck cancer patients undergoing chemo-radiotherapy: Clinical practical recommendations. Crit Rev Oncol Hematol 2016;99:100-6. doi: 10.1016/j. critrevonc.2015.11.010.
27. Quibell R, Fallon M, Mihalyo M, Twycross R, Wilcock A. Ketamine. J Pain Symptom Manage 2015;50(2):268-78. doi: 10.1016/j. jpainsymman.2015.06.002. 